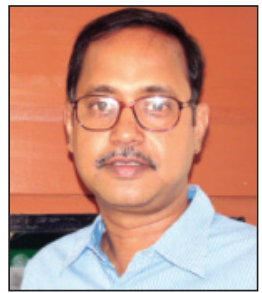

JOURNAL OF MINES, METALS \& FUELS www.jmmf.info

\title{
Detonators can be green, too!
}

Austin Powder Company is a Cleveland, Ohio-based private company that produces a full line of industrial explosives and accessories, including detonator-sensitive and boostersensitive emulsions and detonating cord. The company also provides blasting services in North America, and around the world through subsidiary Austin International. Other subsidiaries include Austin Star Detonator, which offers electric and non-electric detonators, and Austin Detonator, which manufactures detonators in the Czech Republic for sale in Europe and elsewhere. Now nearly 190 year old, Austin Powder Company is trying to reinvent itself both to create a positive image and to be environmentally responsible. It has embarked on innovation.

It's Shock*Star Plastic Free non-electric detonators are designed especially for tunnel applications where plastic remains have to be eliminated from the muck pile. This product could be also beneficial for underground mines where plastic remains negatively influence the material processing. It consists of Shock*Star TS, Shock Tube and low energy detonating cord.In addition to significant reduction of plastic remains in the muck pile it helps in faster blast preparation. Whole range of Shock*Star TS delays is available $(25-9,000 \mathrm{~ms})$. Other details are: detonator shell material- Aluminum, Base charge $720 \mathrm{mg}$, Water pressure resistance $0.005 \mathrm{MPa} / 7$ days, Temperature range for application from $-30^{\circ} \mathrm{C}$ to $+60^{\circ} \mathrm{C}$, Shelf life (storage conditions) 2 years $\left(-30^{\circ} \mathrm{C}\right.$ to $\left.+40^{\circ} \mathrm{C}\right)$, Detonator type-Delay $\mathrm{ms}$, Shock Tube Velocity of detonation 2,000 $\pm 100 \mathrm{~m} / \mathrm{s}$ and Detonating Cord Explosive charge $3.2 \mathrm{~g} / \mathrm{m}$.

So what is the innovation? The author surmises that it has possibly replaced the plastic tube by a tube of similar property cellulosic material of natural fibers, etc. Natural fibers can be obtained from plants including wood, agriculture crops grown mainly to obtain fibers (such as flax, hemp, and sisal), and as the by-products of some crops that have other primary uses (such as wheat, corn, rice, and sugar, etc.) using appropriate physical and chemical treatments. The plants mostly consist of cellulose, hemicellulose, and lignin. Pectin, ash, and extractives can be found in lower quantities. The properties of fibers are different depending on the processing technologies, which affect the chemical composition and morphology of natural fibers. The key characteristics of natural fibers have been introduced in terms of general cellulosic fibers (pulp), cellulose nanofiber, and regenerated cellulose fibers (Fig. below):
Molded pulp products/bio-foams and cellulose-based films used as tubes with Shock*Star Plastic Free nonelectric detonators

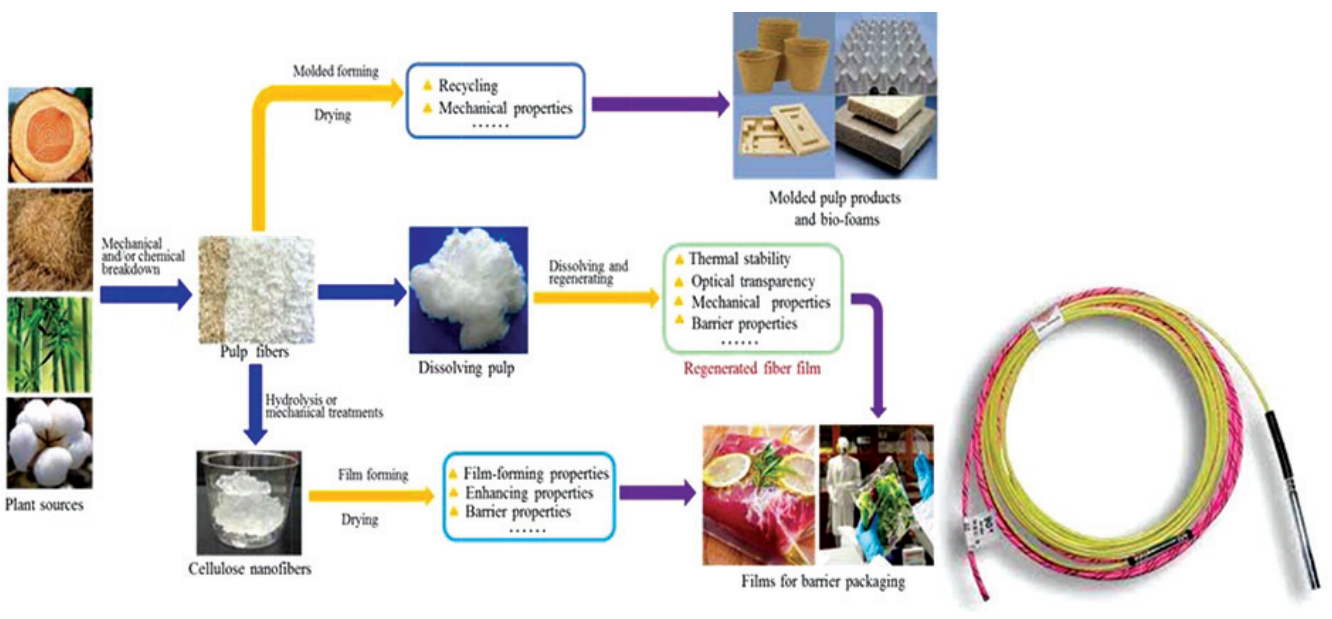

